\title{
Rancang Bangun Aplikasi Barang Habis Pakai di Laboratorium Teknik Elektro Universitas Bangka Belitung
}

\author{
Asmar ${ }^{1}$, Ridwan Andrian² \\ Jurusan Teknik Elektro, Fakultas Teknik, Universitas Bangka Belitung1 \\ Jurusan Teknik Elektro, Fakultas Teknik, Universitas Bangka Belitung2 \\ asmar@ubb.ac.id'1,*ridwan-andrian@ubb.ac.id²
}

\begin{abstract}
The Electrical Engineering Laboratory of the University of Bangka Belitung is a place where students carry out practicum activities and research activities. In the University of Bangka Belitung Electrical Engineering laboratory, there are many electronic components and electrical equipment used by students for practicum activities and research activities. Electronic components and electrical equipment are categorized as consumables because these components are only used once or twice. Analysis in making the application is done by observing the system that is running and then designed using Microsoft Access. The application that will be made is expected to facilitate laboratory managers in the process of recording data on the use of goods. In addition, the application is also expected to provide information regarding the availability of goods so that it can facilitate planning for the procurement of consumables and making reports and storing data digitally.
\end{abstract}

Keywords: Laboratory, Consumables, Microsoft Access

\section{INTISARI}

Laboratorium Teknik Elektro Universitas Bangka Belitung merupakan tempat mahasiswa melakukan aktifitas praktikum dan kegiatan penelitian. Di laboratorium Teknik Elektro Universitas Bangka Belitung banyak sekali komponen elektronika dan peralatan listrik yang digunakan mahasiswa untuk kegiatan praktikum maupun kegiatan penelitian. Komponen elektronika dan peralatan listrik dikategorikan sebagai bahan habis pakai dikarenakan komponen tersebut hanya satu atau dua kali pakai. Analisis dalam pembuatan aplikasi dilakukan dengan cara observasi terhadap sistem yang berjalan kemudian didesain menggunakan Microsoft Access. Aplikasi yang akan dibuat diharapkan dapat memudahkan pengelola laboratorium dalam proses perekaman data penggunaan barang. Selain itu, aplikasi juga diharapkan dapat memberikan informasi mengenai ketersediaan barang sehingga dapat memudahkan perencanaan pengadaan barang habis pakai dan pembuatan laporan dan penyimpanan data secara digital.

Kata kunci: Laboratorium, Bahan Habis Pakai, Microsoft Access

\section{PENDAHULUAN}

Kegiatan inventaris barang pada laboratorium Teknik Elektro telah menggunakan aplikasi tetapi hanya terbatas pada barang-barang yang sifatnya barang pinjam pakai, sedangkan barang habis pakai atau barang persediaan belum terdapat aplikasi untuk mengelola barang-barang tersebut. Karena jumlah dan jenis barang tersebut jumlahnya juga relatif banyak maka perlu dibuat suatu aplikasi untuk mengontrol penggunaan barang-barang tersebut.

Analisis dalam pembuatan aplikasi dilakukan dengan cara observasi terhadap sistem yang berjalan kemudian didesain menggunakan Microsoft Access. Aplikasi yang akan dibuat diharapkan dapat memudahkan pengelola laboratorium dalam proses perekaman data penggunaan barang. Selain itu, aplikasi juga diharapkan dapat memberikan informasi mengenai ketersediaan barang sehingga dapat memudahkan perencanaan pengadaan barang habis pakai.

\section{LANDASAN TEORI}

Inventaris barang habis pakai merupakan database bahan umum kategori 1 (satu) maupun kategori 2 (dua) untuk kegiatan pendidikan, penelitian dan pengabdian mahasiswa dan dosen serta masyarakat umum, dimana jumlahnya mengalami perubahan bisa bertambah atau berkurang yang diakibatkan oleh 
kegiatan yang dilakukan oleh mahasiswa, dosen atau masyarakat umum. Dalam pengendalian ini dibutuhkan sistem yang terintegrasi.

Saat ini perkembangan teknologi begitu pesat namun ternyata masih banyak instansi yang melakukan sistem inventaris secara manual. Hal ini dinilai kurang efektif karena dengan pencatatan secara manual sering terjadi kesalahan-kesalahan. Adapun tujuan dari penerapan sistem informasi inventaris barang adalah sebagai berikut:

1. Dapat mempermudah dan mempercepat pelayanan,

2. Meningkatkan mutu pelayanan,

3. Mempermudah pencarian data barang,

4. Mempermudah pembuatan laporan.

Salah satu software yang digunakan dalam pembuatan aplikasi untuk inventaris barang adalah Microsoft Access. Software tersebut adalah sebuah program aplikasi basis data komputer relasional yang ditujukan untuk kalangan rumahan dan perusahaan kecil hingga menengah. Microsoft Access merupakan aplikasi yang dibuat oleh Microsof Office yang berguna untuk mengolah data dan juga berfungsi untuk merancang, membuat dan mengolah beragam jenis data.

\section{METODE PENELITIAN}

Secara garis besar metode penelitian dibagi menjadi beberapa tahap yaitu sebagai berikut:

1. Melakukan pengamatan sistem yang berjalan,

2. Melakukan analisis sistem yang berjalan dengan cara indentifikasi permasalahan,

3. Merancang aplikasi

Sistem penggunaan barang habis pakai di laboratorium Teknik Elektro ditunjukkan pada Gambar 1.

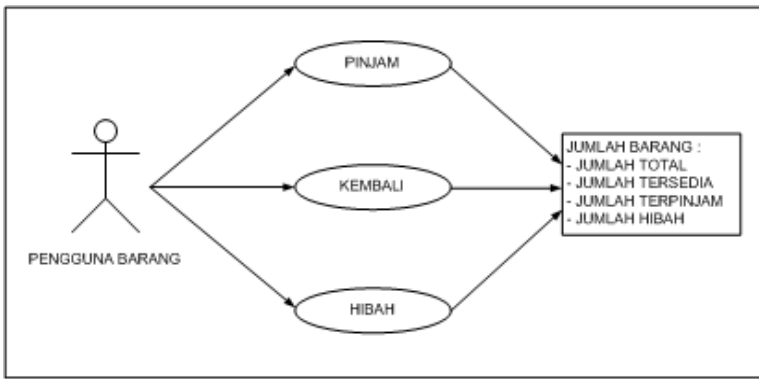

Gambar 1. Sistem penggunaan barang habis pakai di laboratorium Teknik Elektro
Pengguna barang (dosen atau mahasiswa) mengajukan permintaan barang. Jika barang yang akan digunakan sifatnya hanya bisa dipakai satu kali (seperti akrilic, lem, kabel, dll) maka pengeluaran barang tersebut dicatat sebagai barang hibah. Jika barang yang diminta sifatnya dapat digunakan kembali, maka dicatat sebagai barang pinjam. Barang yang dapat digunakan kembali juga dapat dihibahkan, misalnya untuk kepentingan pumbuatan tugas akhir. Pengelola laboratorium mendata ketersediaan barang, yaitu jumlah total pengadaan, jumlah tersedia, jumlah yang terpinjam dan jumlah yang dihibahkan

Sebelum pembuatan aplikasi, harus diidentifikasi permasalahan dalam inventaris barang laboratorium. Hasil identifikasi digunakan untuk pembuatan aplikasi. Tahapan-tahapan yang dilakukan dalam penelitian diperlihatkan pada Gambar 1.

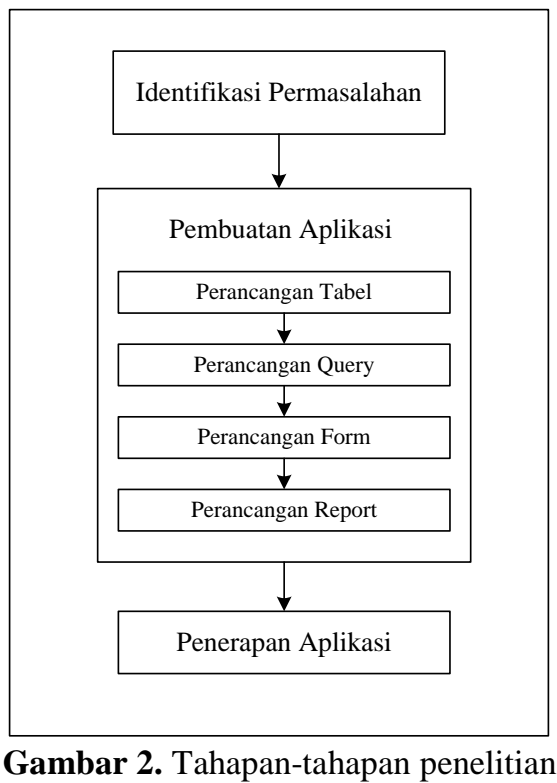

Sistem penggunaan barang tersebut kemudian akan dianalisis untuk menentukan proses perancangan aplikasi yang akan dibuat, yang meliputi :

1. Perancangan table,

2. Perancangan query,

3. Perancangan form,

4. Perancangan report,

5. Perancangan macros dan modules.

Hubungan tabel-tabel tersebut pada query diatur agar proses peminjaman, pengembalian, jumlah ketersediaan barang dan pembuatan laporan dapat dilakukan dengan mudah dan cepat serta dapat memberikan informasi yang diperlukan. Perancangan 
form dan report dibuat dengan mempertimbangkan kemudahan dalam proses memasukkan data dan dapat menyajikan informasi-informasi yang diperlukan.

\section{HASIL PENELITIAN DAN PEMBAHASAN}

Pada Gambar 3 memperlihatkan tampilan awal (switchboard) ketika aplikasi dijalankan. Aplikasi untuk barang habis pakai telah terintegrasi dengan aplikasi barang inventaris yang telah dibuat pada penelitian sebelumnya.

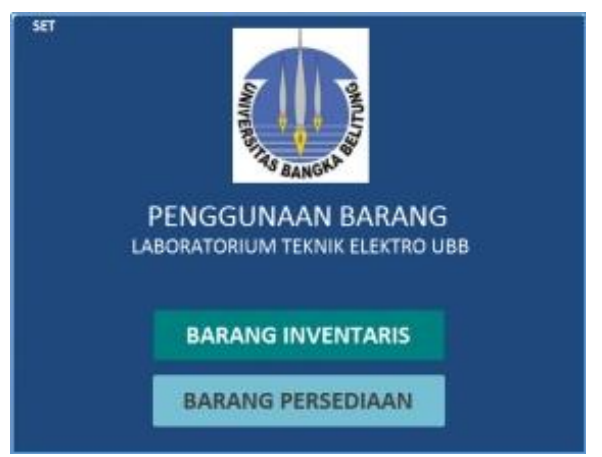

Gambar 3. Switchboard integrasi aplikasi barang inventaris dan barang habis pakai (barang persediaan)

Gambar 4 memperlihatkan switchboard untuk barang habis pakai (barang persediaan). Form peminjaman, pengembalian dan pengubahan data dilindingi dengan password karena proses tersebut hanya boleh dilakukan oleh pengelola laboratorium.

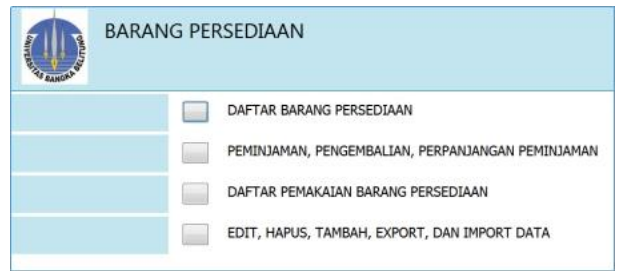

Gambar 4. Switchboard barang habis pakai/barang persediaan

Form daftar barang persediaan (Gambar 4) berisi informasi mengenai kode barang, nama barang, jumlah total, jumlah tersedia, jumlah terpakai (dipinjam dan dihibahkan), tempat simpan, dan lain-lain. Form tersebut dilengkapi dengan tombol daftar peminjaman. Ketika tombol tersebut ditekan, maka akan diberikan informasi mengenai siapa saja yang telah menggunakan barang yang dipilih pada form daftar barang persediaan.

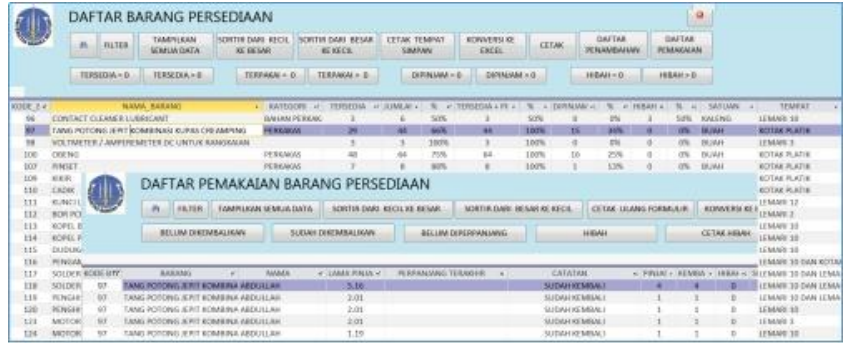

Gambar 5. Form daftar barang

Form daftar pemakaian barang (Gambar 6) memberikan informasi mengenai identitas pengguna barang, jenis penggunaan (hibah atau pinjam), lama peminjaman, dan lain-lain. Dari Form tersebut juga dapat ditampilkan barang-barang yang belum dikembalikan, sudah dikembalikan, hibah, belum diperpanjang peminjamannya, dan lain lain.

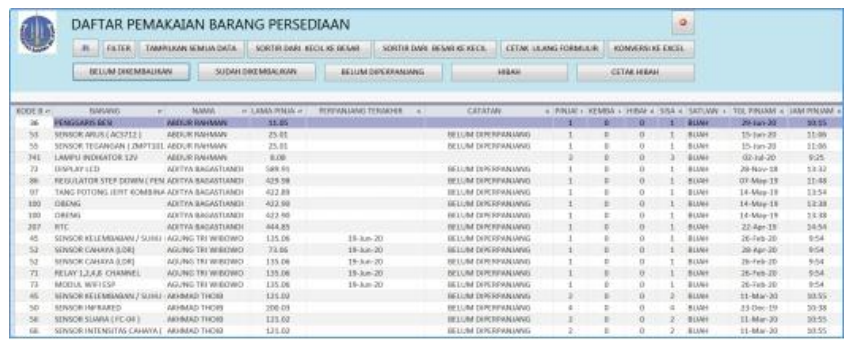

Gambar 6. Daftar pemakaian barang

Form untuk peminjaman diperlihatkan pada Gambar 7. Untuk melakukan proses peminjaman barang, operator cukup memasukkan nomor identitas kemudian aplikasi akan mencari identitas lengkap peminjam pada tabel identitas. Jika suatu barang telah terpinjam selama lebih dari 14 hari dan peminjam hendak meminjam barang yang lain, maka aplikasi akan memberikan pesan kepada operator bahwa terdapat barang yang dipinjam lebih dari 14 hari.

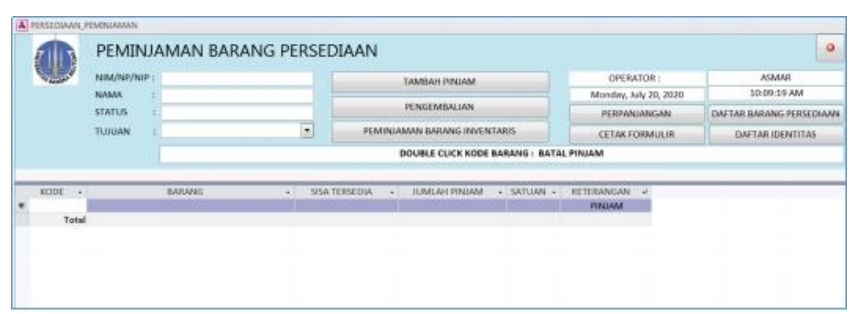

Gambar 7. Form peminjaman barang

Proses input data barang cukup dengan menginput kode barang, jumlah barang yang akan dipinjam atau diminta, dan jenis permintaan (pinjam atau hibah). Aplikasi secara otomatis akan memperbarui jumlah ketersediaan barang. Form peminjaman juga menyediakan tombol untuk membuka report formulir 
peminjaman yang telah terisi data yang lengkap dan hanya perlu ditandatangani.

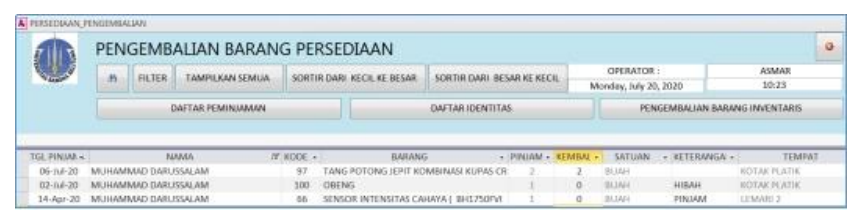

Gambar 8. Form Pengembalian Barang

Pada proses pengembalian barang, operator akan diminta untuk memasukkan nomor identitas peminjam, hal ini bertujuan agar aplikasi hanya menampilkan barang yang dipinjam sesuai dengan nomor identitas yang dimasukkan (Gambar 8). Proses pengempalian barang dilakukan dengan memasukkan jumlah barang yang dikembalikan, sedangkan sisa barang ditetapkan oleh operator apakah akan dihibahkan atau tetap dalam kondisi dipinjam.

Form-form pada aplikasi juga dilengkapi tomboltombol untuk memudahkan operator dalam memperoleh informasi yaitu tombol untuk mencari data, memfilter data, mengurutkan data, dan mencetak laporan.

Aplikasi yang dibuat dapat menghasilkan 3 jenis laporan (report), yaitu kondisi daftar ketersediaan barang (Gambar 9), formulir peminjaman (Gambar 10), dan daftar pemakaian barang (Gambar 11). Aplikasi juga memungkinkan untuk melakukan konversi data menjadi file excel sehingga operator dapat membuat laporan dan mengolah data dalam format excel.

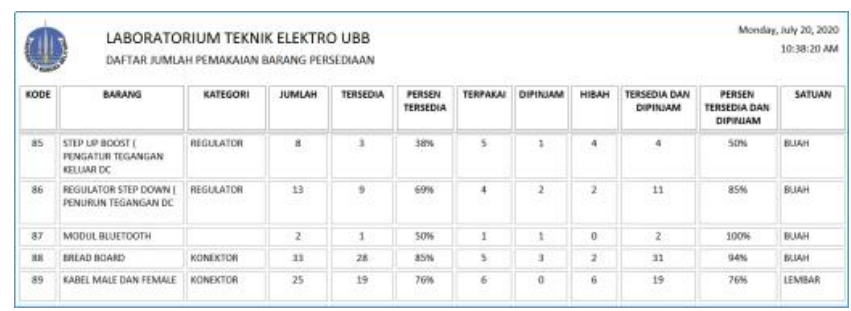

Gambar 9. Contoh report ketersediaan barang

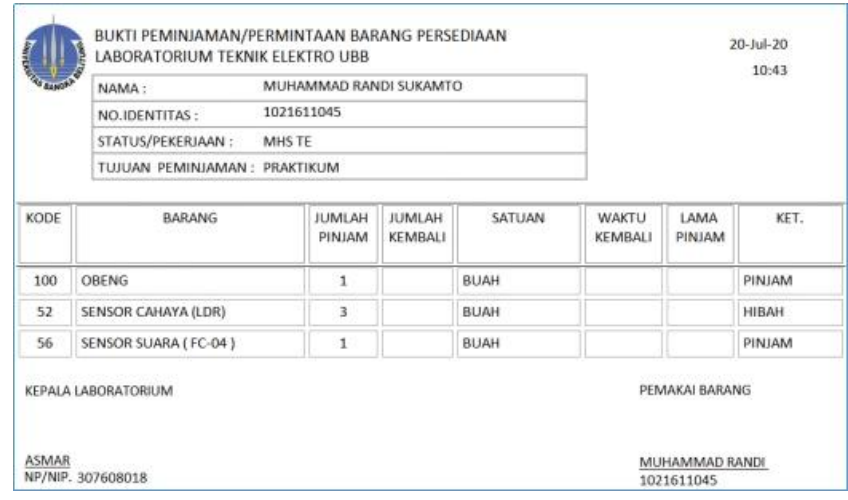

Gambar 10. Contoh report formulir peminjaman

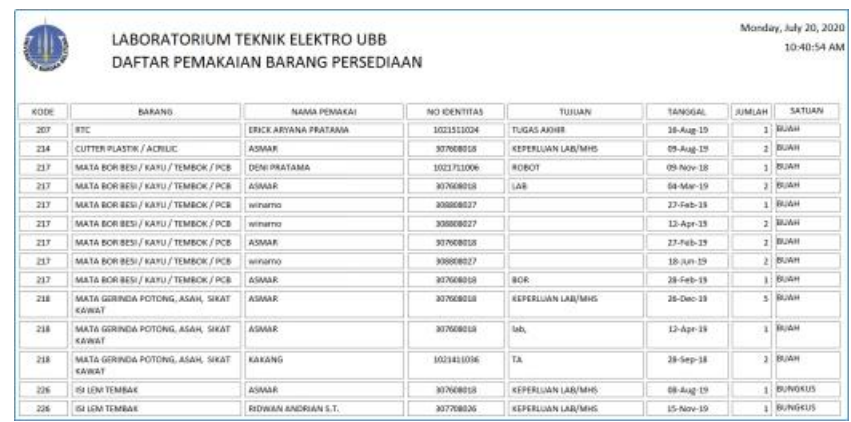

Gambar 11. Contoh report daftar pemakaian barang

Agar aplikasi dapat diakses melalui jaringan, maka setiap komputer diatur dalam satu homegroup yang sama dan folder tempat aplikasi tersebut berada harus dibagikan (shared) ke komputer lain. Aplikasi tersebut juga dapat diakses lebih dari satu komputer secara bersamaan dan proses perekaman dan penampilan data tetap dapat berlangsung dengan baik.

\section{KESIMPULAN}

Hasil dari penelitian ini sudah diimplementasikan dan membantu dan mempermudah pengelolaan laboratorium Jurusan Teknik Elektro Universitas Bangka Belitung dalam melakukan pengendalian dalam pemakaian bahan habis pakai serta mempermudah pembuatan laporan dan perencanaan barang habis pakai ke depannya.

\section{REFERENSI}

[1]. Jogiyanto, Analisis dan Disain Sistem Informasi Pendekatan Terstruktur Teori dan Praktek Aplikasi Bisnis, Cetakan Ketiga, Andi, Yogyakarta, 2005.

[2]. David M. Kroenke, Database Processing Fundamentals, Design, and Implementation, Eight Edition, Pretince Hall, 2002. 
Jurnal ECOTIPE, Volume 8, No.2, Oktober 2021, Hal. 131-135

p-ISSN 2355-5068, e-ISSN 2622-4852

Akreditasi Kemenristekdikti (SINTA 4), SK. No.10/E/KPT/2019

DOI: 10.33019/jurnalecotipe.v8i2.2590

[3]. Madcoms, Membangun Aplikasi Stok Inventori, Andi Publisher, 2015.

[4]. Asmar dan Ghiri B. P., Rancang Bangun Aplikasi Sistem Inventory dengan Barcode di Laboratorium Teknik Elektro Universitas Bangka Belitung, Jurnal Ecotipe Vol. 8 No.1, pp.33-38, 2021.

[5]. Kukuh Nugroho, Jaringan Komputer, Media Tera, 2016.

[6]. A. D. Maharani dan S. Wiyono, Sistem Informasi Inventaris Laboratorium Berbasis Web Pada Stikes Bhakti Mandala Husada Slawi, Jurnal Informatika, 2016.

[7]. H. R. Puspitawati, H. W. Herwanto, Perancangan Sistem Informasi Invetarisasi Labotorium Berbasis Web, Jurnal Tekno, Vol.17, 2012. 